\title{
Rapid Electrochemical Monitoring of Tyrosine by Poly as a Sensitive Sensor and its Applications in Pharmaceutical Samples
} (Riboflavin) Modified Carbon Nanotube Paste Electrode

\author{
Edwin Santhan D' Souza ${ }^{1,2} \mathbb{C}^{\mathbb{D}}$, Jamballi G. Manjunatha ${ }^{1, * \mathbb{C}}$, Raril Chenthattil ${ }^{1(\mathbb{D}}$, Girish Tigari ${ }^{(\mathbb{D})}$, \\ Doddarasinakere K. Ravishankar ${ }^{3}$ \\ 1 Department of Chemistry, FMKMC College, Madikeri, Constituent College of Mangalore University, Karnataka, India; \\ manju1853@gmail.com (J.G.M); edwin_shal@yahoo.in $\quad$ (E.S.S.); rarilchenthatti19633@gmail.com (R.C.); \\ girishtigari@gmail.com (G.T); \\ 2 Department of Chemistry, St. Philomena College, Puttur, Karnataka, India \\ 3 Department of Chemistry, Sri. Mahadeshwara govt. First Grade College, Kollegal, Chamarajanagar, Karnataka, India \\ * Correspondence: manju1853@gmail.com;
}

Scopus Author ID 34872832000

Received: 3.02.2021; Revised: 8.03.2021; Accepted: 11.03.2021; Published: 25.03.2021

\begin{abstract}
A poly(riboflavin) modified carbon nanotube paste electrode (PRFMCNTPE) is employed as a compatible and electrocatalytic sensor for the determination of Tyrosine (TYR). The analysis and assessment are carried out through differential pulse voltammetry (DPV) and Cyclic Voltammetry $(\mathrm{CV})$. The surface of the intended sensor is examined through Field Emission Scanning Electron Microscopy (FE-SEM). The modified electrode shows the outstanding electrocatalytic effect for TYR with high selectivity and sensitivity as compared to carbon nanotube paste electrode (CNTPE). The electro-oxidation peak current of TYR and its concentration is found linear from $2 \mu \mathrm{M}$ to $10 \mu \mathrm{M}$ with a detection limit (LOD) of $0.45 \mu \mathrm{M}$. The developed sensor is productively applied for the determination of TYR in pharmaceutical samples like Tyrosine capsules. The adapted electrode shows good stability, excellent reproducibility, and remarkable sensitivity.
\end{abstract}

Keywords: Poly(riboflavin); tyrosine; electrochemical sensor; carbon nanotube paste electrode; voltammetry.

(C) 2021 by the authors. This article is an open-access article distributed under the terms and conditions of the Creative Commons Attribution (CC BY) license (https://creativecommons.org/licenses/by/4.0/).

\section{Introduction}

Amino acids are the building blocks of proteins that make up most parts of our body. They are highly essential for developing human organs such as muscles, hormones, and the nervous system [1]. Among the amino acids, Tyrosine (TYR) (4- hydroxyphenylalanine) is a well-known essential aromatic amino acid for nutritional balance in herbivore's bodies. A human being's healthy state is correlated with the amount of TYR present in the body [2-3]. TYR is determined as a precursor for thyroxine, dopamine, adrenaline, and non-adrenaline hormones or neurotransmitters [4-5]. It is a vital constituent of proteins, which is indispensable in humans nutrition for maintaining and establishing a supportive balance of nitrogen in the human body [6-7], and its deficiency may produce hypochondria, depression [8-9]. A high TYR concentration in the culture medium can cause increased sister chromatid exchange, and a high level of TYR may also lead to Parkinson's disease [10-11]. The low intensity of TYR 
in the body due to the hereditary condition called phenylketonuria; the body does not develop phenylalanine, one of the amino acids [12-13]. Phenylalanine is essential to synthesize TYR in the body. Since it is scarcely present in vegetables, it is sometimes added to dietary food products and pharmaceutical products [14-15]. TYR is converted into melanin by skin cells, a dark pigment that protects the human being against ultraviolet light's destructive effects [16]. Thus, TYR has been of great interest in research studies.

It is very significant to advance the investigative techniques for the speedy determination of TYR for medical and quality control. Plentiful methods have been reported for the recognition of TYR, such as liquid chromatography [17-18], gas chromatography [19-20], High-Performance Liquid Chromatography [21], Chemiluminescence [22-23], and spectrophotometry [24-25]. However, some of the drawbacks of these techniques include low selectivity and sensitivity, interference, expensive instrumentation, and large consumption, limiting their applications [26-27]. Hence, there is a demand for a rapid, uncomplicated, susceptible, and suitable method to solve these problems. Electrochemical processes tender a convenient mode to examine biologically vital molecules [28-30]. TYR is an electroactive molecule; therefore, the electrochemical method is used for its analysis. This method provides a simple, fast, sensitive, and accurate way of analyzing biomolecules in real samples [31-53].

Carbon nanotube paste electrode (CNTPE) is widely used as a working electrode in analytical chemistry due to its various applications, such as trouble-free and speedy preparation, convenient surface regeneration, and broad potential range, apart from being economical. The advantages of modified carbon nanotube paste electrodes have recently provided substantial improvements in biologically important molecules' electrochemical performance [54-62]. Various electrochemical methods are reported to determine TYR, and carbon-based electrodes are more frequently used electrodes in voltammetry [63-64].

This work's main intention is to design a novel electrochemical sensor for the ultrasensitive determination of TYR. In this study, the electrode modification is performed by preparing poly (riboflavin) at the CNTPE to investigate TYR using CV and DPV. In addition to this, the important parameters of modified electrodes for the electro-oxidation of TYR are also studied. TYR is evaluated in drug samples. The electrochemical oxidation mechanism of TYR at the PRFMCNTPE is shown in Scheme 1.

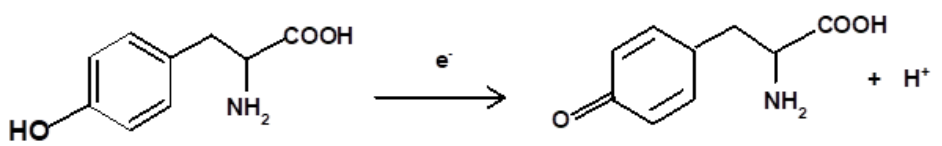

Scheme 1. Structure and oxidation reaction mechanism of TYR.

\section{Materials and Methods}

\subsection{Instrumentation.}

Electrochemical studies are done with a model CHI 6038 E (USA). Poly (riboflavin) modified carbon nanotube paste electrode (PRFMCNTPE) and carbon nanotube paste electrode (CNTPE) are used as the working electrodes, having a cavity of $3.00 \mathrm{~mm}$ diameter. A platinum wire was used as an auxiliary electrode and a Saturated Calomel Electrode (SCE) as a reference electrode to complete the circuit. These electrodes are immersed in a cell having the analyte. A personal computer is used to manage and save the statistics. FE-SEM was performed using the instrument operating at $5.00 \mathrm{kV}$ (DST-PURSE Laboratory, Mangalore University). 


\subsection{Reagents and stock solutions.}

Riboflavin, Tartrazine, and Tyrosine are purchased from Molychem Chemicals, Mumbai, India, and used without any refinement. All other chemicals used are of analytical grade. $\mathrm{RF}$ is dissolved in $0.1 \mathrm{M} \mathrm{NaOH}$ to get a standard solution of $1 \times 10^{-4} \mathrm{M}$ concentration. The solutions of Tyrosine $\left(1 \times 10^{-4} \mathrm{M}\right)$ and Tartrazine $\left(1 \times 10^{-4} \mathrm{M}\right)$ are dissolved using $0.1 \mathrm{~N}$ $\mathrm{H}_{2} \mathrm{SO}_{4}$ and distilled water. $0.1 \mathrm{M} \mathrm{Na}_{2} \mathrm{HPO}_{4}$ and $0.1 \mathrm{M} \mathrm{NaH}_{2} \mathrm{PO}_{4}$ are mixed in appropriate proportions to obtain $0.1 \mathrm{M}$ PBS with different $\mathrm{pH}$ values.

\subsection{Preparation of CNTPE.}

The CNTPE is prepared by grinding carbon nanotube paste with silicon oil in the proportion of 60:40 (w/w) in a mortar and pestle for 30 minutes to form a homogeneous paste. A portion of the paste is then filled carefully into the Teflon tube's $3 \mathrm{~mm}$ internal diameter cavity without any air gap. Electrical contact is established using a copper wire fixed to the graphite and inserted into the Teflon tube. The electrode's outer surface is renewed mechanically, and a smooth, shiny surface of the electrode is attained by polishing the surface with polishing paper.

\section{Results and Discussion}

\subsection{Characterisation of the electrodes by FE-SEM}

FE-SEM is one of the effective tools to investigate the surface morphology of the electrodes. Fig. 1 illustrates the FE-SEM interpreted images of the different electrodes.

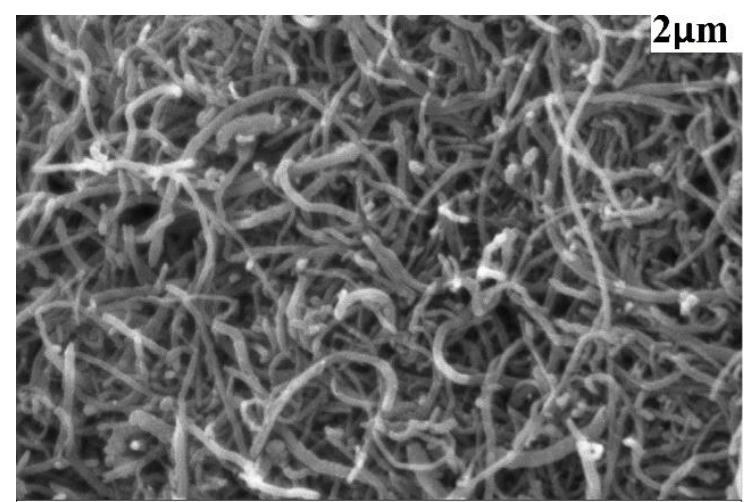

(a)

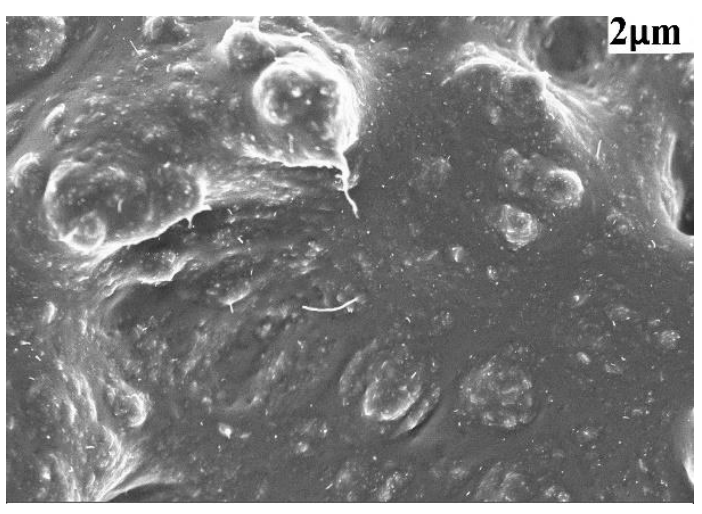

(b)

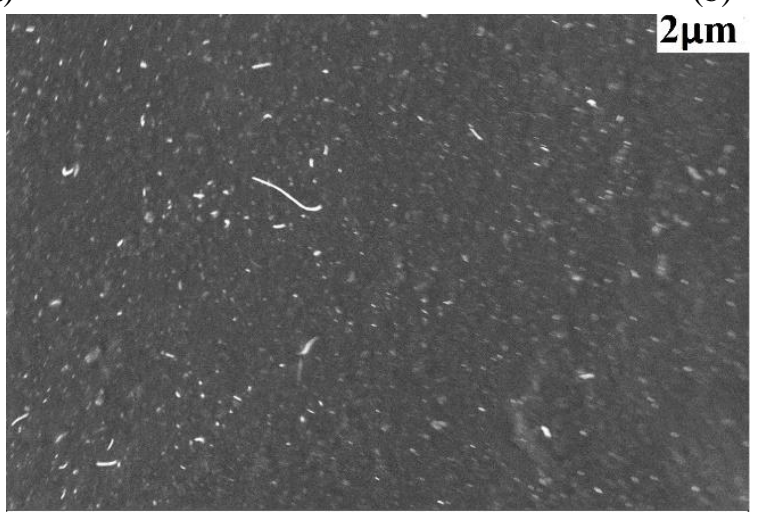

(c)

Figure 1. (a) CNT, (b) CNTPE, and (c) PRFMCNTPE. 
Fig. 1(a), 1(b), and 1(c) exhibit the morphological characters of CNT, CNTPE, and PRFMCNTPE. The FE-SEM image shows the tube-like fiber in CNT, whereas the image of CNTPE indicates the non-uniform distribution and homogeneous deposition of RF as a malleable pact on the carbon nanotube is observed in PRFMCNTPE. This confirms that the surface of the CNTPE is modified by RF, and the surface area of the electrode is increased.

\subsection{Preparation of PRFMCNTPE.}

A solution of RF $\left(1 \times 10^{-4} \mathrm{M}\right)$ in PBS $(0.1 \mathrm{M}, \mathrm{pH} 7.5)$ is placed in a cell. The solution is scanned in the potential range from -1.0 to $1.5 \mathrm{~V}$ at the sweep rate of $0.1 \mathrm{~V} / \mathrm{s}$ for 10 cycles to obtain PRFMCNTPE. Distilled water has been used to soak the electrode to get rid of untreated RF residual on the electrode surface. Fig. 2 displays the cyclic voltammograms for the electropolymerization of riboflavin.

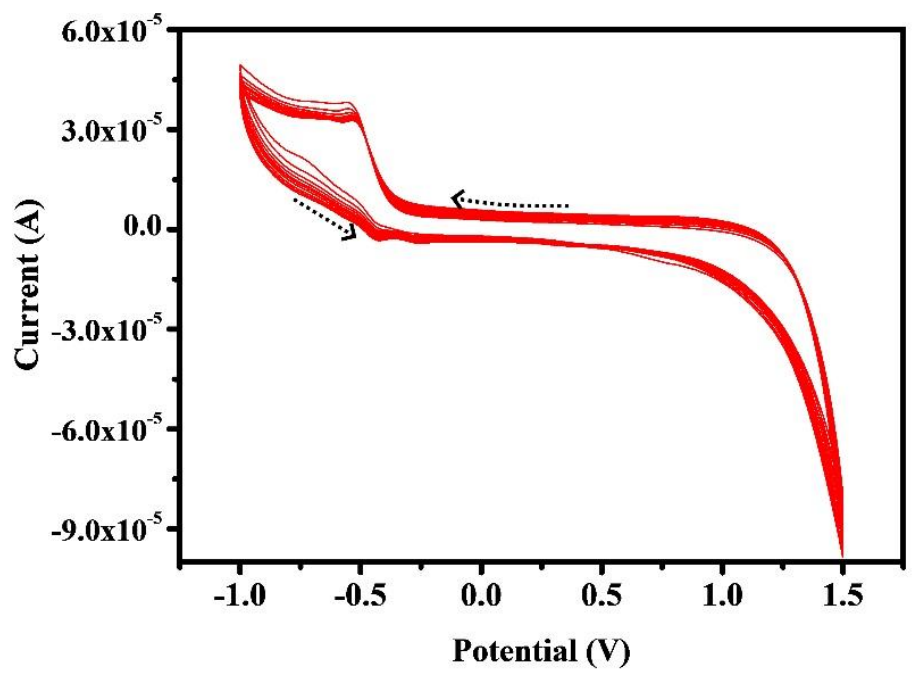

Figure 2. The electropolymerization of RF $(0.1 \mathrm{mM})$ in PBS at $7.5 \mathrm{pH}$ for 10 cycles at the sweep rate of $0.1 \mathrm{~V} / \mathrm{s}$.

\subsection{Electrochemical oxidation of TYR at PRFMCNTPE.}

The electrochemical behavior of TYR is investigated through DPV and CV (higher sensitivity and low background current response). The voltammograms developed for TYR at CNTPE and PRFMCNTPE in 0.1 M PBS of pH 7.0 were depicted in Fig. 3. DPV is used to investigate the electrochemical behavior of TYR at CNTPE and PRFMCNTPE. Fig. 3(a) shows the differential pulse voltammogram of $1 \times 10^{-4} \mathrm{M}$, TYR in $0.1 \mathrm{M}$ PBS at $\mathrm{pH} 7.0$ at CNTPE (curve b), and PRFMCNTPE (curve a). Peaks are detected for both the electrodes individually at the potential range of $0.40 \mathrm{~V}$ to $0.90 \mathrm{~V}$. The oxidation peak displays a peak at $0.595 \mathrm{~V}$ for the modified electrode, which is higher than the oxidation peak of CNTPE having peak potential at $0.664 \mathrm{~V}$.

The behavior of TYR is studied cyclic voltammetrically, and the voltammogram developed is represented in Fig. 3b. It shows that the oxidation peak of TYR at PRFMCNTPE (curve a) is produced at $0.667 \mathrm{~V}$, with a higher anodic peak current when compared to CNTPE (curve b). Curve c shows the blank response obtained at PRFMCNTPE. No peak appeared for the blank solution. Consequently, the reduction peak is not observed during the electroanalysis of TYR, stating that the oxidation process is irreversible. 


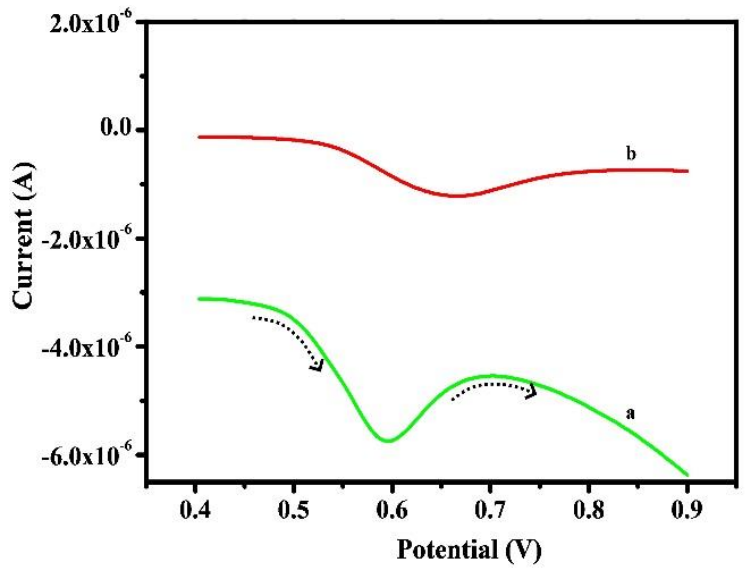

(a)

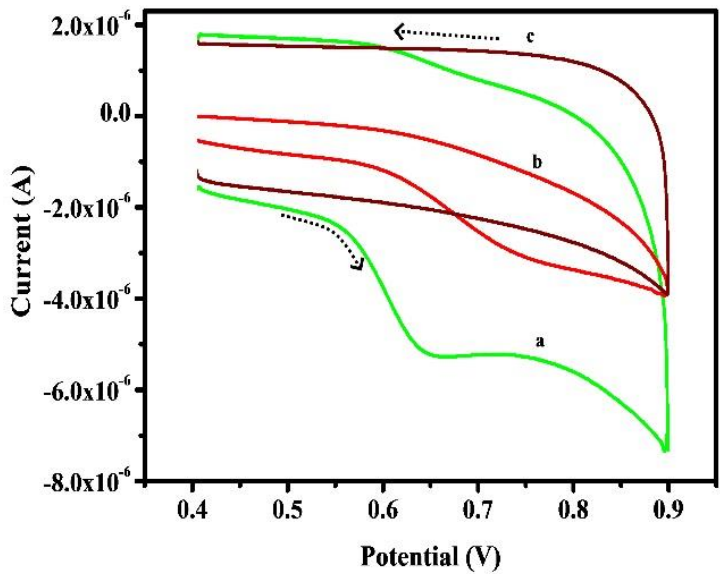

(b)

Figure 3. (a) Differential pulse Voltammogram of TYR at CNTPE (curve b) and PRFMCNTPE (curve a) in 0.1 M PBS, $7.0 \mathrm{pH}$ at the sweep rate of $0.1 \mathrm{~V} / \mathrm{s}$. (b) Cyclic Voltammogram of TYR at PRFMCNTPE (curve a), CNTPE (curve b) and blank (curve c) in $0.1 \mathrm{M} \mathrm{PBS}, 7.0 \mathrm{pH}$ at the sweep rate of $0.1 \mathrm{~V} / \mathrm{s}$.

\subsection{Effect of solution $\mathrm{pH}$.}

The role of solution $\mathrm{pH}$ on TYR oxidation is studied using CV using $0.1 \mathrm{M}$ PBS at the scan rate of $0.1 \mathrm{~V} / \mathrm{s}$ on PRFMCNTPE. The effect of $\mathrm{pH}$ in the range of 6.0 to 8.0 on the anodic peak current is shown in Fig. 4a. With the increase in $\mathrm{pH}$ of the solution from 6.0 to 8.0, the oxidation peak potential also increases. It reaches a maximum at $7.0 \mathrm{pH}$, and the peak potential is shifted negatively. Beyond $7.0 \mathrm{pH}$, a great decrease in the oxidation peak current is observed. Hence $\mathrm{pH} 7.0$ is chosen throughout the experiment for further studies of TYR. The plot of the solution $\mathrm{pH}$ and the oxidation potential $\left(\mathrm{E}_{\mathrm{pa}}\right)$ is obtained linearly with linear regression equation $\mathrm{E}_{\mathrm{pa}}(\mathrm{V})=1.056-0.057 \mathrm{pH}(\mathrm{R}=0.99)$ (Fig. 4b). This shows the linear dependency of peak potential on buffer $\mathrm{pH}$. The obtained slope of $0.057 \mathrm{~V} / \mathrm{pH}$ is close to the theoretical value of slope $0.058 \mathrm{~V} / \mathrm{pH}$. It confirms that the proportion of proton and electron involved in the catalytic reaction is found to be in the ratio of $1: 1$. Therefore, the oxidation of TYR is a single electron transfer process [65].

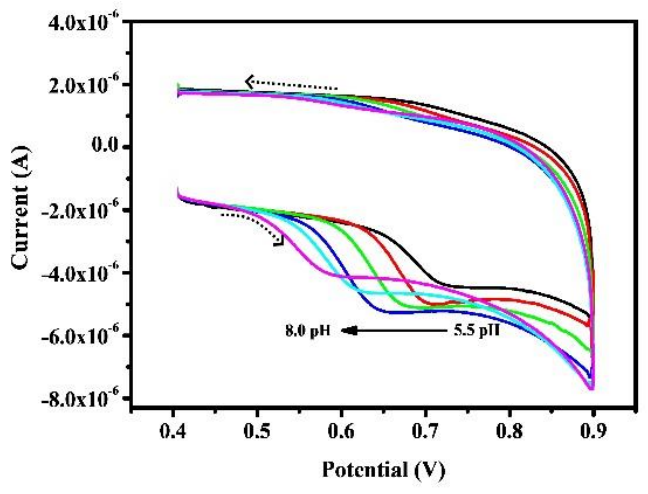

(a)

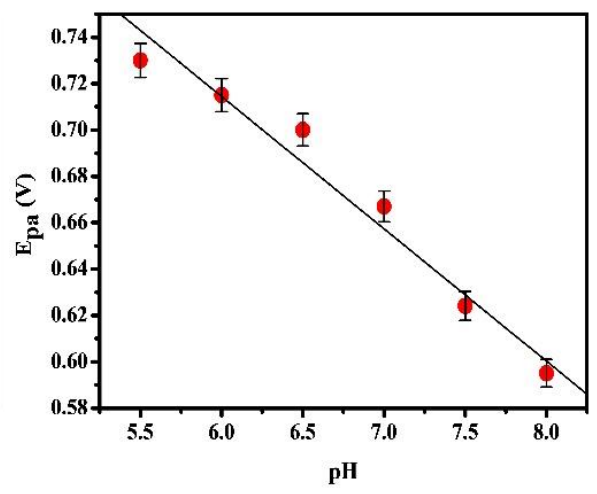

(b)

Figure 4. (a) Cyclic voltammogram of TYR $\left(1 \times 10^{-4} \mathrm{M}\right)$ at PRFMCNTPE in $0.1 \mathrm{M}$ PBS at different $\mathrm{pH}$ values, 5.5, 6.0, 6.5, 7.0, 7.5, 8.0 (b) Epa vs. $\mathrm{pH}$.

\subsection{Effect of scan rate.}

Information regarding the electrochemical reaction can be generally deduced from the rapport between scan rate and peak current. The impact of scan rate on the electro-oxidation of $0.1 \mathrm{mM}$ TYR at PRFMCNTPE is calculated at different scan rates 0.05, 0.1, 0.125, 0.150, 
$0.175,0.200,0.250 \mathrm{~V} / \mathrm{s}$ and the derived cyclic voltammogram is shown in Fig. 5a. The plot of the anodic peak current $\left(\mathrm{I}_{\mathrm{pa}}\right)$ versus scan rate exhibits good linearity (fig. $5 \mathrm{~b}$ ) with a linear regression equation $\mathrm{I}_{\mathrm{pa}}(\mu \mathrm{A})=1.89+29.76 v(\mathrm{mV} / \mathrm{s})$ with a correlation coefficient of 0.990 . This shows the linear dependency of scan rate and peak current. This shows that an adsorption controlled process [66-67] occurs at PRFMCNTPE.

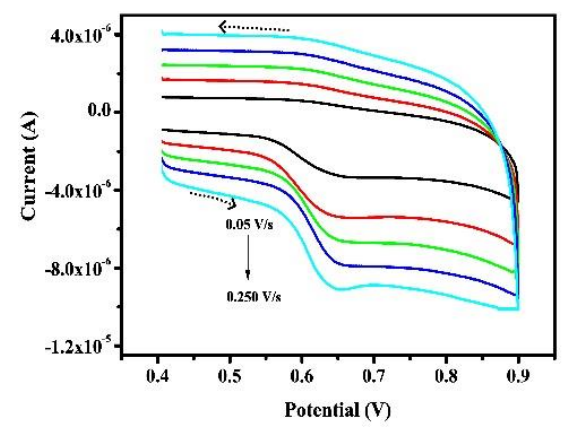

(a)

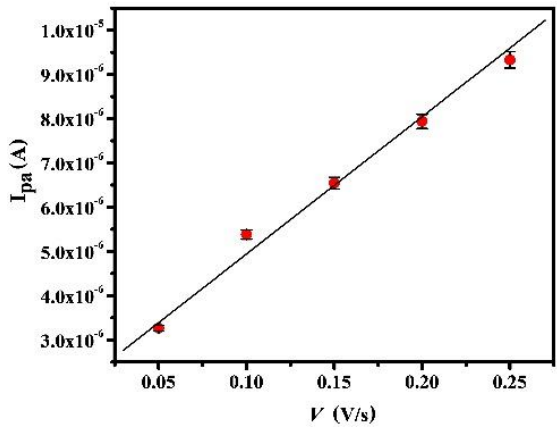

(b)

Figure 5. (a) Cyclic Voltammogram of TYR $\left(1 \times 10^{-4} \mathrm{M}\right)$ at PRFMCNTPE in $0.1 \mathrm{M}$ PBS of pH 7.0 at different scan rate $(0.05$, to 0.250$)$. (b) Anodic peak current $\left(\mathrm{I}_{\mathrm{pa}}\right)$ vs. scan rate $(v)$.

\subsection{Simultaneous determination of TYR and TZ at PRFMCNTPE through CV and DPV.}

The electrochemical behavior of TYR with TZ is investigated using an unmodified electrode related to interferences of TYR due to the oxidation potential of two targets. By using the modified electrodes, CV (Fig. 6a) obtained shows well-defined anodic peaks detected at $0.662 \mathrm{~V}$ and $0.916 \mathrm{~V}$ for the oxidation of TYR and TZ, respectively. Therefore, employing PRFMCNTPE enables the determination of the two analytes simultaneously without any serious interference. Simultaneous determination of TYR and TZ is also investigated using DPV. From Fig. 6(b) shows that two different oxidation peaks are obtained separately for TYR and TZ with potentials of $0.600 \mathrm{~V}$ and $0.851 \mathrm{~V}$, respectively. This data indicates that the modified electrode current response is found at a higher value than the response of the CNTPE.

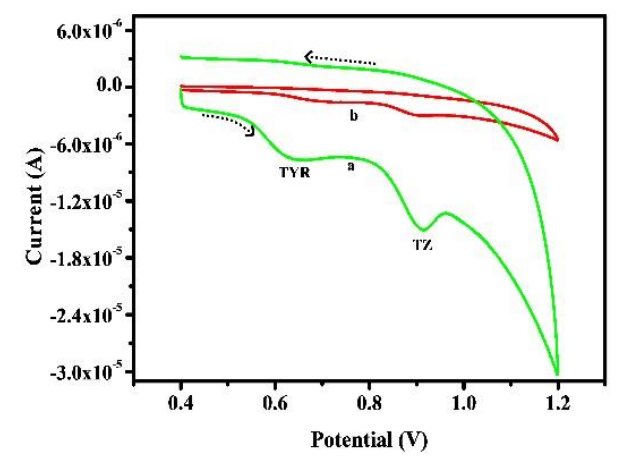

(a)

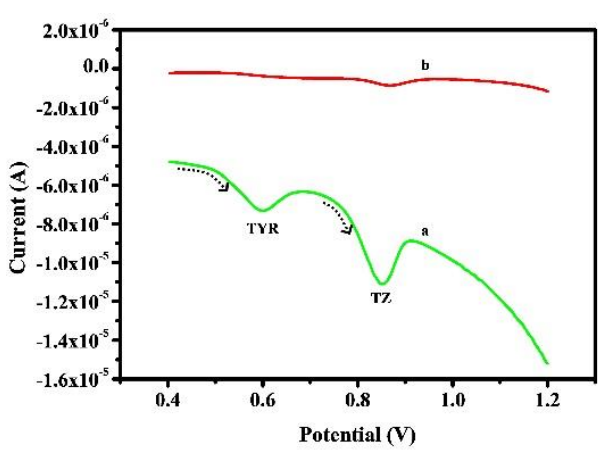

(b)

Figure 6. (a) Cyclic Voltammogram of the solution containing TYR $\left(1 \times 10^{-4} \mathrm{M}\right)$ and TZ $\left(1 \times 10^{-4} \mathrm{M}\right)$ in $0.1 \mathrm{M}$ PBS at pH 7.0 at PRFMCNTPE (curve a) and CNTPE (curve b). (b) DPVs of the solution containing TYR $\left(1 \times 10^{-4} \mathrm{M}\right)$ and TZ $\left(1 \times 10^{-4} \mathrm{M}\right)$ in PBS $(0.1 \mathrm{M}, \mathrm{pH} 7.0)$ at the PRFMCNTPE and CNTPE.

\subsection{Calibration curve and detection limit.}

$\mathrm{CV}$ is used to find the relation between the concentration of TYR and oxidation peak. The outcome of the study is plotted in Fig. 7. The oxidation peak current is linearly proportional to TYR concentration in between the range of $2 \times 10^{-6} \mathrm{M}$ to $1 \times 10^{-5} \mathrm{M}, 1.5 \times 10^{-5} \mathrm{M}$ to $7 \times 10^{-5} \mathrm{M}$ and has the equation of linear regression $\mathrm{I}_{\mathrm{pa}}(\mu \mathrm{A})=2.39 \times 10^{-6}+0.0793 \mathrm{C}_{\mathrm{TYR}}(\mathrm{M}),(\mathrm{R}=0.99)$. 
This shows the linear dependency of peak current and concentration. LOD and limit of quantification (LOQ) are obtained from $3 \sigma / \mathrm{m}$ and $10 \sigma / \mathrm{m}$, respectively [68]. $\sigma$ is calculated as the standard deviation of $5 \mathrm{CV}$ measurements in the blank solution, and $\mathrm{m}$ is the slope obtained in the calibration curve. LOD and LOQ are determined, and the values obtained are $0.45 \mu \mathrm{M}$ and $1.52 \mu \mathrm{M}$, respectively. The values are compared to several modified electrodes' values and found to be closer to one another (Table 1) [69-72].

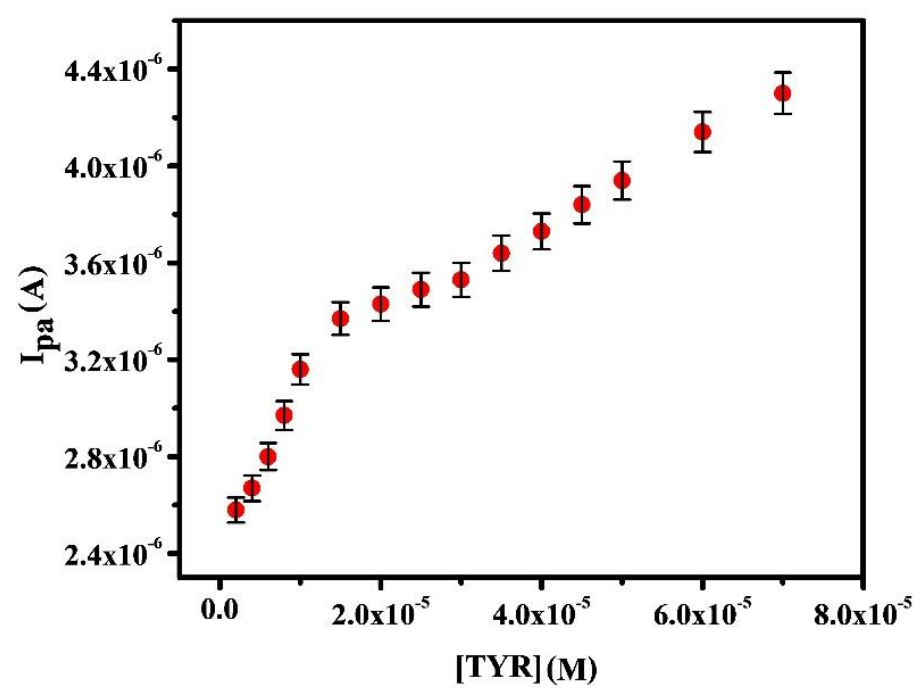

Figure 7. Calibration plot for the determination of TYR at PRFMCNTPE in PBS (0.1 M, pH 7.0) at the scan rate of $0.1 \mathrm{~V} / \mathrm{s}$.

Table 1. Linear range and limit of detection produced using PRFMCNTPE for the determination of TYR with other methods.

\begin{tabular}{|c|c|c|c|}
\hline \\
\hline Working electrode & Linear range $/ \mu \mathrm{M}$ & Detection limit $/ \mu \mathrm{M}$ & Ref. \\
\hline $\begin{array}{c}\text { thiolated } \beta \text {-cyclodextrins } \\
\text { modified } \\
\text { gold electrode }\end{array}$ & $36-240.0$ & 12.0 & [69] \\
\hline $\begin{array}{l}\text { Carbon fibers modified } \\
\text { carbon paste electrode }\end{array}$ & $0.2-107.0$ & 0.1 & {$[70]$} \\
\hline $\begin{array}{l}\text { Electrochemically reduced } \\
\text { Graphene oxide modified } \\
\text { glassy carbon electrode }\end{array}$ & $0.5-80.0$ & 0.2 & {$[71]$} \\
\hline $\begin{array}{l}\text { Sodium dodecyl sulfate and } \\
\text { multi-walled nanotube } \\
\text { modified CPE }\end{array}$ & $0.4-100$ & 0.1 & {$[72]$} \\
\hline PRFMCNTPE & 2.0 to 10.0 & 0.45 & Present work \\
\hline
\end{tabular}

\subsection{Repeatability and stability.}

Repeatability of TYR at PRFMCNTPE in 0.1 M PBS with pH 7.0 at the scan rate of $0.1 \mathrm{~V} / \mathrm{s}$ is studied using a CV technique. PRFMCNTPE shows good repeatability for 5 consecutive cycles by varying the solution concentration and manifests a relative standard deviation (RSD) of $2.42 \%$ by keeping the same electrode. The electrode's stability is also checked by running the electrode for 20 cycles and can be calculated by using the percentage degradation formula.

$$
\text { Percentage degradation }=\frac{I_{p n}}{I_{p 1}} \times 100
$$


In the above expression, $\mathrm{I}_{\mathrm{pn}}$ is the peak current at the last cycle, and $\mathrm{I}_{\mathrm{pl}}$ is the peak current at the first cycle. It is found that even after 20 cycles, about $88 \%$ of the initial current is regained. This statistic indicates that PRFMCNTPE has excellent stability of the developed sensor.

\subsection{Analytical applications in real sample analysis.}

To evaluate the modified electrodes' applicability in real samples, the electrode has to be tested with real samples. In this work, TYR is determined in the Tyrobless tablet through the descriptive method. In CV technique, the pharmaceutical drug Tyrobless is used for real sample analysis to determine the presence of TYR. The standard addition method is used to detecting the concentration and amount of TYR in the sample. The results of this analysis have shown that PRFMCNTPE has exceptional sensitivity, selectivity, and steadiness to TYR in the real sample of a pharmaceutical drug with $96.3 \%$ to $99 \%$ recovery (Table 2).

\begin{tabular}{|c|c|c|c|}
\hline Sl. No & Added $(\mu \mathrm{M})$ & Found $(\mu \mathrm{M})$ & Recovery (\%) \\
\hline 1 & 70 & 67.41 & 96.3 \\
\hline 2 & 80 & 79.2 & 99.0 \\
\hline
\end{tabular}

\section{Conclusions}

The new PRFMCNTPE has been prepared, and the electrochemical response of TYR is determined. The electrode is easy to prepare, economical, steady, and easily renewable, and shows good catalytic activity for the oxidation of TYR. The oxidation peak potential is observed at $0.667 \mathrm{~V}$ with an oxidation peak current of $-5.31 \mu \mathrm{A}$. This method is adsorption controlled with one electron transfer and irreversible. The methods such as DPV and CV have shown remarkable selectivity, sensitivity, additional reply with exceptional repeatability and constancy towards TYR at PRFMCNTPE. LOD and LOQ are $0.45 \mu \mathrm{M}$ and $1.52 \mu \mathrm{M}$, respectively. The developed sensor is used to determine TYR content in a pharmaceutical drug with a good recovery.

\section{Funding}

This research received no external funding.

\section{Acknowledgments}

We are grateful to acknowledge the financial support from VGST, Bangalore, under Research Project No. KSTePS/VGST-KFIST (L1) 2016-2017/GRD-559/2017-2018/126/333, 21/11/2017.

\section{Conflicts of Interest}

The authors declare no conflict of interest.

\section{References}

1. Kelly B.; Pearce, E.L. Amino Assets: How Amino Acids Support Immunity. Cell Metabolism 2020, 32, 154175, https://doi.org/10.1016/j.cmet.2020.06.010. 
2. Beitollahi, H.; Nejad, F.G. A Carbon Paste Electrode Modified by Graphene Oxide/Fe3O4@SiO2/Ionic Liquid Nanocomposite for Voltammetric Determination of Acetaminophen in the Presence of Tyrosine. Russ J Electrochem 2019, 55, 1162-1170, https://doi.org/10.1134/S1023193519120024.

3. Zil'berg, R.A.; Maistrenko, V.N.; Kabirova, L.R.; Gus'kov V.Y.; Khamitov E.M.; Dubrovskii, D.I. A Voltammetric Sensor Based on a 3,4,9,10-Perylenetetracarboxylic Acid Composite for the Recognition and Determination of Tyrosine Enantiomers. $J$ Anal Chem 2020, 75, 101-110, https://doi.org/10.1134/S1061934820010189.

4. Carlsson, A.; Lindqvist, M.; Dependence of 5-HT and catecholamine synthesis on concentrations of precursor amino-acids in rat brain. Naunyn-'Schmiedeberg's Arch. Pharmacol. 1978, 303, 157-164, https://doi.org/10.1007/BF00508062.

5. Currie, P.J.; Chang, N.; Luo, S.; Anderson, G.H. Microdialysis as a tool to measure dietary and regional effects on the complete profile of extracellular amino acids in the hypothalamus of rats. Life Sci. 1995, 57, 1911-1923, https://doi.org/10.1016/0024-3205(95)02178-1.

6. Fang, B.; Liu, H.; Wang, G.; Zhou, Y.; Li, M.; Yu, Y. The electrochemical behavior and direct determination of tyrosine at a glassy carbon electrode modified with poly (9-aminoacridine). Ann. Chim. 2007, 97, 10051013, https://doi.org/10.1002/adic.200790085.

7. Yarkaeva, Y.A.; Dubrovskii, D.I.; Zil’berg, R.A.; Maistrenko, V.N.; Kornilov V.M. A Voltammetric Sensor Based on a 3,4,9,10-Perylenetetracarboxylic Acid Composite for the Recognition and Determination of Tyrosine Enantiomers. J Anal Chem 2020, 75, 1537-1545, https://doi.org/10.1134/S1061934820110143.

8. Rahimi-Mohseni, M; Raoof, J.B.; Ojani, R. Aghajanzadeh, T.A.; Hashkavayi, A.B. Development of a new paper based nano-biosensor using the co-catalytic effect of tyrosinase from banana peel tissue (Musa Cavendish) and functionalized silica nanoparticles for voltammetric determination of L-tyrosine. Int. J. Biolog. Macromol. 2018, 113, 648-654, https://doi.org/10.1016/j.ijbiomac.2018.02.060.

9. Mollarasouli, F.; Serafín, V.; Campuzano, S.; Yanez-Sedeno, P.; Asadpour-Zeynali, K. Ultrasensitive determination of receptor tyrosine kinase with a label-free electrochemical immunosensor using graphene quantum dots-modified screen-printed electrodes. Anal. Chim. Acta. 2018, 1011, 28-34, https://doi.org/10.1016/j.aca.2018.01.039.

10. Zhou, S.; Wu, H.; Wu, Y.; Shi, H.; Feng, X.; Huang, H.; Song, W. Large surface area carbon material with ordered mesopores for highly selective determination of l-tyrosine in the presence of l-cysteine. Electrochim Acta 2013, 112, 90-94, https://doi.org/10.1016/j.electacta.2013.08.134.

11. Liu, X.; Luo, L.; Ding, Y.; Kang, Z.; Ye, D. Simultaneous determination of L-cysteine and L-tyrosine using $\mathrm{Au}$-nanoparticles/polyeriochrome black T film modified glassy carbon electrode. Bioelectrochemistry 2012, 86, 38-45, https://doi.org/10.1016/j.bioelechem.2012.01.008.

12. Blau, N. Genetics of phenylketonuria: then and now. Hum. Mutat. 2016, 37, 508-515, https://doi.org/10.1002/humu.22980.

13. What are common treatments for phenylketonuria. Available from: https://www.nichd.nih.gov/health/topics/pku/conditioninfo/treatments 2016, 9.

14. Rahman, M.M.; Lopa, N.S.; Kim, K.; Lee, J.J. Selective detection of L-tyrosine in the presence of ascorbic acid, dopamine, and uric acid at poly (thionine)-modified glassy carbon electrode. J Electroanal Chem. 2015, 754, 87-93, https://doi.org/10.1016/j.jelechem.2015.06.018.

15. Hareesha, N.; Manjunatha J.G.; Raril C.; Tigari, G. Sensitive and Selective Electrochemical Resolution of Tyrosine with Ascorbic Acid through the Development of Electropolymerized Alizarin Sodium Sulfonate Modified Carbon Nanotube Paste Electrodes. Chemistryselect 2020, 4, 4559-4567, https://doi.org/10.1002/slct.201900794.

16. Quintana, C.; Suarez, S.; Hernandez, L. Nanostructures on gold electrodes for the development of an Ltyrosine electrochemical sensor based on host-guest supramolecular interactions. Sensors and Actuators B: chemical 2010, 149, 129-135, https://doi.org/10.1016/j.snb.2010.06.011.

17. Gotze, L.; Hegele, A.; Metzelder, S.K.; Renz, H.; Nockher, W.A. Development and clinical application of a LC-MS/MS method for simultaneous determination of various tyrosine kinase inhibitors in human plasma. Clin Chim Acta. 2012, 413, 143-149, https://doi.org/10.1016/j.cca.2011.09.012.

18. Musshoff, F.; Schmidt, P.; Dettmeyer, R.; Priemer, F.; Jachau, K.; Madea, B. Determination of dopamine and dopamine-derived (R)-/(S)-salsolinol and norsalsolinol in various human brain areas using solid-phase extraction and gas chromatography/mass spectrometry. Forensic Sci Int. 2000, 113, 359-366, https://doi.org/10.1016/s0379-0738(00)00225-5.

19. Deng, C.; Deng, Y.; Wang, B.; Yang, X. Gas chromatography-mass spectrometry method for determination of phenylalanine and tyrosine in neonatal blood spots. J Chromatogr B. 2002, 780, 407-413, https://doi.org/10.1016/S1570-0232(02)00632-3.

20. Patel, B.A.; Arundell, M.; Parker, K.H.; Yeoman, M.S. Hare, D.O. Simple and rapid determination of serotonin and catecholamines in biological tissue using high-performance liquid chromatography with electrochemical detection. $J \quad$ Chromatogr $\quad$ B. $2005, \quad 818, \quad$ 269-276, https://doi.org/10.1016/j.jchromb.2005.01.008. 
21. Letellier, S.; Garnier, J. P.; Spy, J.; Bousquet, B. Determination of the L-dopa/L-tyrosine ratio in human plasma by high-performance liquid chromatography: usefulness as a marker in metastatic malignant melanoma. J Chromatogr B. 1997, 696, 9-17, https://doi.org/10.1016/s0378-4347(97)00206-5.

22. Ohtomo, T.; Shukuro, I.; Yoshitaka, T.; Osamu, O. Quenching-Chemiluminescence Determination of Trace Amounts of 1-Tyrosine Contained in Dietary Supplement by Chemiluminescence Reaction of an IronPhthalocyanine Complex. J Anal Methods Chem 2012, 2012, https://doi.org/doi:10.1155/2012/520248.

23. Zhang, L.; Teshima, N.; Hasebe, T.; Kurihara, M.; Kawashima, T. Flow-injection determination of trace amounts of dopamine by chemiluminescence detection. Talanta 1999, 50, 677-683, https://doi.org/10.1016/s0039-9140(99)00164-2.

24. Chrastil, J. Spectrophotometric determination of tryptophan and tyrosine in peptides and proteins based on new color reactions. Anal. Biochem. 1986, 158, 443-446, https://doi.org/10.1016/0003-2697(86)90573-7.

25. Da Cruz Vieira, I.; Fatibello-Filho, O. Spectrophotometric determination of methyldopa and dopamine in pharmaceutical formulations using crude extract of sweet potato root (Ipomoea batatas (L.) Lam.) as enzymatic source. Talanta 1998, 46, 559-564, https://doi.org/10.1016/s0039-9140(97)00317-2.

26. Nagles, E.; Ibarra, L.; Llanos, J.P.; Hurtado, J.; Garcia-Beltran, O. Development of a novel electrochemical sensor based on cobalt (II) complex useful in the detection of dopamine in presence of ascorbic acid and uric acid. J Electroanal Chem. 2017, 788, 387-343, https://doi.org/10.1016/j.jelechem.2017.01.057.

27. Pekin, M.; Bayraktepe, D. E.; Yazan, Z. Electrochemical sensor based on a sepiolite clay nanoparticle-based electrochemical sensor for ascorbic acid detection in real-life samples. Ionics 2017, 23, 3487-3495, https://doi.org/10.1007/s11581-017-2132-8.

28. Raril, C.; Manjuntha, J.G. A simple approach for the electrochemical determination of vanillin at ionic surfactant modified graphene paste electrode. Michrochem. J. 2020, 153, https://doi.org/10.1016/j.microc.2019.104575.

29. Manjunatha, J.G.; Deraman, M. Graphene paste electrode modified with sodium dodecyl sulfate surfactant for the determination of dopamine, ascorbic acid and uric acid. Anal Bioanal Electrochem. 2017, 9, 198-213.

30. Manjunatha, J.G. A new electrochemical sensor based on modified carbon nanotube mixture past electrode for voltammetric determination of resorcinol. Asian J Pharm Clin Res. 2017, 10, 295-300, https://doi.org/10.22159/ajpcr.2017.v10i12.21028.

31. Tigari, G.; Manjunatha, J.G. Optimized Voltammetric Experiment for the Determination of Phloroglucinol at Surfactant Modified Carbon Nanotube Paste Electrode. Instrum Exp Tech 2020 63, 750-757, https://doi.org/10.1134/S0020441220050139.

32. Kazemipour, M.; Ansari, M.; Mohammadi, A.; Beitollahi, H.; Ahmadi, R. Use of adsorptive square-wave anodic stripping voltammetry at carbon paste electrode for the determination of amlodipine besylate in pharmaceutical preparations. J. Anal. Chem. 2009, 64, 65-70, https://doi.org/10.1134/S1061934809010134.

33. Ensafi, A.A.; Abarghoui, M.M.; Rezaei, B. A new non-enzymatic glucose sensor based on copper/porous silicon nanocomposite. Electrochim. Acta 2014, https://doi.org/10.1016/j.electacta.2014.01.031.

34. Beitollahi, H.; Movahedifar, F.; Tajik, S.; Jahani, S. A Review on the Effects of Introducing CNTs in the Modification Process of Electrochemical Sensors. Electroanalysis. 2019, 31, 1195-1203, https://doi.org/10.1002/elan.201800370.

35. Tajik, S.; Beitollahi, H. A Sensitive Chlorpromazine Voltammetric Sensor Based on Graphene Oxide Modified Glassy Carbon Electrode. Anal. Bioanal. Chem. Res. 2019, 6, 171-182, https://doi.org/10.22036/ABCR.2018.89229.1154.

36. Gururaj, K.J.; Kumara Swamy, B.E. Electrochemical Synthesis of Titanium Nano Particles at Carbon Paste Electrodes and Its Applications as an Electrochemical Sensor for the Determination of Acetaminophen in Paracetamol Tablets. Soft Nanosci. Lett. 2013, 3, 20-22, https://doi.org/10.4236/snl.2013.34A006.

37. Tahernejad-Javazmi, F.; Shabani-Nooshabadi, M.; Karimi-Maleh, H. Analysis of glutathione in the presence of acetaminophen and tyrosine via an amplified electrode with $\mathrm{MgO} / \mathrm{SWCNTs}$ as a sensor in the hemolyzed erythrocyte. Talanta 2018, 176, 208-213, https://doi.org/10.1016/j.talanta.2017.08.027.

38. Jayadevappa, H.; Sathish, R.; Kumara, S.B.E.; Aruna, S.; Mohan, K.; Shashanka, R. Preparation of NiO/ZnO hybrid nanoparticles for electrochemical sensing of dopamine and uric acid. Chem. Sensors 2012, 2,

39. Sathish, R.; Chaira, D.; Shashanka, R.; Kumara, S.B.E. Synthesis of Silver Nanoparticles and their Applications. Anal. Bioanal. Electrochem. 2013, 5, 455-466.

40. Karimi-Maleh, H.; Ganjali, M.R.; Norouzi, P.; Bananezhad, A. Amplified nanostructure electrochemical sensor for simultaneous determination of captopril, acetaminophen, tyrosine and hydrochlorothiazide. Mater. Sci. Eng. C 2017, 73, 472-477, https://doi.org/10.1016/j.msec.2016.12.094.

41. Cheraghi, S.; Taher, M.A.; Karimi-Maleh, H. Highly sensitive square wave voltammetric sensor employing $\mathrm{CdO} / \mathrm{SWCNTs}$ and room temperature ionic liquid for analysis of vanillin and folic acid in food samples. J. Food Compos. Anal. 2017, 62, 254-259, https://doi.org/10.1016/j.jfca.2017.06.006.

42. Fouladgar, M.; Karimi-Maleh, H. Ionic liquid/multiwall carbon nanotubes paste electrode for square wave voltammetric determination of methyldopa. Ionics 2013, 19, 1163-1170, https://doi.org/10.1007/s11581012-0832-7. 
43. Shashanka, R.; Chaira, D.; Kumara Swamy, B.E. Effect of $\mathrm{Y}_{2} \mathrm{O}_{3}$ Nanoparticles on Corrosion Study of Spark Plasma Sintered Duplex and Ferritic Stainless Steel Samples by Linear Sweep Voltammetric Method. Arch. Metall. Mater. 2018, 63, 749-763, https://doi.org/10.24425/122401.

44. Shashanka, R. Effect of Sintering Temperature on the Pitting Corrosion of Ball Milled Duplex Stainless Steel by using Linear Sweep Voltammetry. Anal. Bioanal. Electrochem. 2018, 10, 349-361.

45. Taherkhani, A.; Tahoora, J.; Hadadzadeh, H.; Karimi-Maleh, H.; Beitollahi, H.; Taghavi, M.; Karimi, F. $\mathrm{ZnO}$ nanoparticle-modified ionic liquid-carbon paste electrode for voltammetric determination of folic acid in food and pharmaceutical samples. Ionics 2014, 20, 421-429, https://doi.org/10.1007/s11581-013-0992-0.

46. Shashanka, R. Kumaraswamy, B.E. Biosynthesis of Silver Nanoparticles Using Leaves of Acacia Melanoxylon and their Application as Dopamine and Hydrogen Peroxide Sensors. Phys. Chem. Res. 2020, 8, 1-18, https://doi.org/10.22036/PCR.2019.205211.1688.

47. Gururaj, K.J.; Kumara Swamy, B.E.; Sharma, S.C.; Santoyo-Flores, J.J. Analyzing electron transfer properties of ferrocene in gasoline by cyclic voltammetry and theoretical methods. Microchem. J. 2020, 158, 1-12, https://doi.org/10.1016/j.microc.2020.105116.

48. Ganjali, M. R.; Beitollahi, H.; Zaimbashi, R.; Tajik, S.; Rezapour, M.; Larijani, B. Voltammetric Determination of Dopamine Using Glassy Carbon Electrode Modified with $\mathrm{ZnO} / \mathrm{Al}_{2} \mathrm{O}_{3}$ Nanocomposite. Int. J. Electrochem. Sci. 2018, 13, 2519-2529, https://doi.org/10.20964/2018.03.11.

49. Motaghi, M. M.; Beitollahi, H.; Tajik, S.; Hosseinzadeh, R. Nanostructure Electrochemical Sensor for Voltammetric Determination of Vitamin C in the Presence of Vitamin B6: Application to Real Sample Analysis. Int. J. Electrochem. Sci. 2016, 11, 7849-7860, https://doi.org/10.20964/2016.09.60.

50. Beitollahi, H.; Tajik, S.; Asadi, M.H.; Biparva, P. Application of a modified graphene nanosheet paste electrode for voltammetric determination of methyldopa in urine and pharmaceutical formulation. J. Anal. Sci.Technol. 2014, 29, https://doi.org/10.1186/s40543-014-0029-y.

51. Manjunatha, J.G.; Kumara Swamy, B.E.; Shreenivas M.T.; Mamatha, G.P. Selective Determination of Dopamine in the Presence of Ascorbic Acid Using a Poly (Nicotinic Acid) Modified Carbon Paste Electrode. Anal. Bioanal. Electrochem. 2012, 4, 225-237.

52. Manjunathaa, J.G.; Kumara, S.B.E.; Deramana, M.; Mamatha, G.P. Simultaneous Determination Of Ascorbic Acid, Dopamine And Uric Acid At Poly (Aniline Blue) Modified Carbon Paste Electrode: A Cyclic Voltammetric Study. Int J Pharm Pharm Sci 2013, 5, 355-361.

53. Manjunathaa, J.G.; Deraman. M.; Basri, N.H.; Talib, I.A. Selective detection of dopamine in the presence of uric acid using polymerized phthalo blue film modified carbon paste electrode. Advanced Materials Research 2014, 895, 447-451.

54. Kalachar, H.C.B.; Basavanna, S.; Viswanatha, R.; Arthoba Naik, Y.; Ananda Raj, D.; Sudha, P.N. Electrochemical Determination of L Dopa in Mucuna pruriens Seeds, Leaves and Commercial Siddha Product Using Gold Modified Pencil Graphite Electrode. Electroanalysis 2011, 23, 1107-1115, https://doi.org/10.1002/elan.201000558.

55. Ganjali, M.R.; Salimi, H.; Tajik, S.; Beitollahi, H.; Rezapour, M.; Larijani, B. Application of $\mathrm{Fe}_{3} \mathrm{O}_{4} @ \mathrm{SiO}_{2} / \mathrm{MWCNT}$ Film on Glassy Carbon Electrode for the Sensitive Electroanalysis of Levodopa. Int. J. Electrochem. Sci. 2017, 12, 5243-5253, https://doi.org/10.20964/2017.06.88.

56. Soltani, H.; Beitollahi, H.; Hatefi-Mehrjardi, A.H.; Tajik, S.; Torkzadeh-Mahani, M. Voltammetric Determination of Glutathione Using a Modified Single Walled Carbon Nanotubes Paste Electrode. Anal. Bioanal. Electrochem. 2014, 6, 67-79.

57. Valentini, F.; Amine, A.; Orlandocci, S.; Terranova, M.L.; Palleschi, G. Carbon nanotube purification: Preparation and characterization of carbon nanotube paste electrodes. Anal. Chem. 2003, 75, 5413-5421, https://doi.org/10.1021/ac0300237.

58. Tigari, G.; Manjunatha, J.G. A surfactant enhanced novel pencil graphite and carbon nanotube composite paste material as an effective electrochemical sensor for determination of riboflavin. Journal of Science: Advanced Materials and Devices 2020, 5, 56-64, https://doi.org/10.1016/j.jsamd.2019.11.001.

59. Manjunatha, J.G. Electrochemical polymerised graphene paste electrode and application to catechol sensing. Open Chem. Eng. J. 2019, 13, 81-87, https://doi.org/10.2174/1874123101913010081.

60. Manjunatha, J.G.; Kumara, S.B.E.; Deraman, M. Electrochemical Studies of Dopamine, Ascorbic Acid and Their Simultaneous Determination at a Poly(Rosaniline) Modified Carbon Paste Electrode: A Cyclic Voltammetric Study. Anal. Bioanal. Electrochem. 2013, 5, 426-438, http://dx.doi.org/10.2174/1874123101913010081.

61. Tigari, G.; Manjunatha, J.G. Electrochemical Preparation of Poly(arginine)-Modified Carbon Nanotube Paste Electrode and its Application for the Determination of Pyridoxine in the Presence of Riboflavin: An Electroanalytical Approach. J. Anal. Test. 2019, 3, 331-340, https://doi.org/10.1007/s41664-019-00116-w.

62. Manjunatha, J.G. A surfactant enhanced graphene paste electrode as an effective electrochemical sensor for the sensitive and simultaneous determination of catechol and resorcinol. Chem. Data Collect. 2020, 25, https://doi.org/10.1016/j.cdc.2019.100331.

63. Kavitha, C.; Bramhaiah, K.; John, N.S. Low-cost electrochemical detection of 1-tyrosine using an rGO-Cu modified pencil graphite electrode and its surface orientation on a Ag electrode using an ex situ spectroelectrochemical method. RSC Adv 2020, 10, 22871-22880, https://doi.org/10.1039/D0RA04015K. 
64. Edwin, S D’ Souzaa.; Manjunathaa, J.G.; Raril, C.; Tigari, G.; Pushpanjali, P.A. Polymer Modified Carbon Paste Electrode as a Sensitive Sensor for the Electrochemical Determination of Riboflavin and Its Application in Pharmaceutical and Biological Samples. Anal. Bioanal. Chem. Res. 2020, 7, 461-472, https://dx.doi.org/10.22036/abcr.2020.214882.1445.

65. Manea, F.; Ihos, M.; Remes, A.; Burtica, G.; Schoonman, J. Electrochemical Determination of Diclofenac Sodium in Aqueous Solution on Cu-Doped Zeolite-Expanded Graphite-Epoxy Electrode. Electroanalysis 2010, 22, 2058-2063, https://doi.org/10.1002/elan.201000074.

66. Daneshgar, P.; Norouzi, P.; Ganjali, M.R.; Dinarvand, R.; Moosavi-Movahedi, A.A. Determination of Diclofenac on a Dysprosium Nanowire-Modified Carbon Paste Electrode Accomplished in a Flow Injection System by Advanced Filtering. Sensors 2009, 9, 7903-7918, https://doi.org/10.3390/s91007903.

67. Raoof, J.B.; Ojani, R.; Baghayeri, M. Sensitive voltammetric determination of captopril using a carbon paste electrode modified with nano-TiO2/Ferrocene carboxylic acid. Chin. J. Catal. 2011, 32, 1685-1692, https://doi.org/10.1016/S1872-2067(10)60268-9.

68. Tigari, G.; Manjunatha, J.G. Poly(glutamine) film-coated carbon nanotube paste electrode for the determination of curcumin with vanillin: an electroanalytical approach. Monatsh Chem 2020, 151, 16811688, https://doi.org/10.1007/s00706-020-02700-8.

69. Quintana, C.; Suarez, S.; Hernandez, L. Nanostructures on gold electrodes for the development of an Ltyrosine electrochemical sensor based on host-guest supramolecular interactions. Sensors and Actuators B: chemical 2010, 149, 129-135, https://doi.org/10.1016/j.snb.2010.06.011.

70. Tang, X.; Liu, Y.; Hou, H.; You, T. Electrochemical Determination of L-Tryptophan, L-Tyrosine and LCysteine Using Electrospun Carbon Nanofibers Modified Electrode. Talanta 2010, 15, 2182-2186, https://doi.org/10.1016/j.talanta.2009.11.027.

71. Qin Deng, K.; Zhou, J.; Fang Li, X. Direct electrochemical reduction of graphene oxide and its application to determination of L-tryptophan and L-tyrosine. Colloids Surf. B 2013, 101, 183-18, https://doi.org/10.1016/j.colsurfb.2012.06.007.

72. Ghoreishi, S.M.; Delshad, M.; Khoobi, A. Electrochemical determination of tyrosine in the presence of uric acid at a carbon paste electrode modified with multi-walled carbon nanotubes enhanced by sodium dodecyl sulfate. Cent. Eur. J. Chem. 2012, 10, 1824-1829, https://doi.org/10.2478/s11532-012-0119-x. 